\title{
Effect of Muscle Energy Technique Versus Aerobic Exercise on Chronic Cyclic Pelvic Pain
}

\author{
Khadyga Sayed Abdul Aziz', Hala EL Sayed Mohammad Mowafy², \\ Marwa Esmael Hasanin ${ }^{1}$, Noran Hany Hassan Mahmoud Ghazal ${ }^{1}$ \\ ${ }^{1}$ Department of Physical Therapy for Women's Health, Faculty of Physical Therapy, Cairo University, Cairo, Egypt. \\ ${ }^{2}$ Department of Obstetrics and Gynecology, Faculty of Medicine, Zagazig University, Sharkia, Egypt. \\ *Corresponding Author: Noran Hany Hassan Mahmoud Ghazal, Mobile: 01011269218, Email:noranghazalrr@ gmail.com
}

\begin{abstract}
Background: Chronic cyclic pelvic pain is cyclic pain located in the pelvis and the lower abdominal area, persisting for 6 months or more with no obvious pathological cause for their pain and severe enough to interfere with daily activities. Objective: This study was conducted to compare the effect of aerobic exercise versus the effect of muscle energy technique on chronic cyclic pelvic pain.

Patients and Methods: 30 women complaining of increased pelvic pain of unknown cause lasts more than 6 months diagnosed and referred by their gynecologist. They were divided into two equal groups, Group (A) received muscle energy technique; and Group (B) received aerobic exercise. Both groups were assessed before and after the treatment period (8 weeks) for pain degree by visual analog scale (VAS) and assessment of premenstrual, menstrual, and intermenstrual symptoms by menstrual distress questionnaire scale (MDQ).

Results: The results of this study revealed that there was a significant decrease in VAS and MDQ values posttreatment in both groups (A and B) compared with that pretreatment values, when comparing both groups there was a more significant decrease in the post-treatment values of VAS and MDQ of the group (A) compared with that of the group (B). Conclusion: It can be concluded that both muscle energy technique and aerobic exercise will improve chronic cyclic pelvic pain but muscle energy technique resulted in better improvement as compared to aerobic exercise on chronic cyclic pelvic pain.
\end{abstract}

Keywords: Muscle energy technique, Aerobic exercises, Pelvic pain.

\section{INTRODUCTION}

Chronic pelvic pain (CPP) is described as intermi ttent or persistent discomfort that affects the anatomic pelvis, anterior abdominal wall at or below the umbilic us, lumbosacral back, or buttocks for six months or more and is severe enough to interfere with everyday activities (1). Endometriosis, adenomyosis, pelvic adhesions, pelvic inflammatory disease, tuboovarian abscess, ovarian cysts, ovarian neoplasms, polyps, fibroids, and pelvic venous congestion should all be considered, as should nongynecologic causes such as gastrointestinal, urologic, and psychological issues such as depression. ${ }^{(2)}$.

For many years, the concept that exercise can help prevent and treat symptoms has prevailed, leading to the promotion of the concept that exercise is helpful. Exercise and other behavioral therapies may not only relieve pain but may also remove or reduce the need for medication to regulate menstrual cramps and other symptoms. ${ }^{(3)}$.

Physical activity, which improves blood flow at the pelvic level while also increasing the production of endorphins, may help to relieve pelvic pain caused by excessive prostaglandins release; in fact, it operates as a non-specific analgesic. Aerobic exercises including pelvic tilting, walking, bicycling, and swimming can help treat pelvic pain by improving blood flow, relaxing abdominal muscles, reducing pelvic discomfort, and relieving pressure on nerve centers, pelvic organs, and the alimentary canal ${ }^{(4)}$. Muscle energy technique (MET) is a safe and efficient treatment option for lumbopelvic discomfort MET is one of the most widely used therapy techniques for improving elasticity in contractile and non-contractile tissues. MET is a manual treatment that is becoming increasingly popular since it looks to be safe and mild, and it is thought to be beneficial in a wide range of patients. The muscular energy approach has been recommended for treating muscle imbalances in the lumbopelvic region, such as pelvic asymmetry, for many years. MET is an effective technique for treating pain in various parts of the body ranging from the pelvis to the neck and even the elbow ${ }^{(5)}$.

The study aimed to compare the effect of aerobic exercise versus the effect of muscle energy technique on Chronic cyclic pelvic pain.

\section{PATIENTS AND METHODS}

This study was conducted on thirty women aged between 25 to 35 years. They were selected randomly from the outpatient clinic of Obstetrics and Gynecology at Zagazig University Hospitals according to the following criteria:

Inclusive criteria: Thirty women complaining of increased pelvic pain of unknown cause lasts more than 6 months diagnosed and referred by their gynecologist. All women had a regular menstrual period and their BMI ranged between 20 to 25 . Their age ranged between 25 35 years old.

\section{Exclusion criteria:}

This article is an open access article distributed under the terms and conditions of the Creative Commons Attribution (CC BY-SA) license (http://creativecommons.org/licenses/by/4.0/) 
Participants were excluded if they met one of the following criteria: Patients with congenital uterine anomalies. Patients with intrinsic pelvic pathology including endometriosis, acute or chronic pelvic inflammatory disease, cervicitis, benign or malignant gynecologic tumors, or uterine pathology including adenomyosis or leiomyoma and postoperative adhesions. Irregular or infrequent menstrual cycles. Patients with heavy menstrual bleeding (HMB). Patient with any previous (neurological or musculoskeletal).Age over 35 or less than 25 years old. Patient suffering from any uncontrolled conditions

\section{Ethical Considerations:}

An approval of the study was obtained from Cairo University academic and ethical committee. Every patient signed an informed written consent for acceptance of the operation. This work has been carried out in accordance with The Code of Ethics of the World Medical Association (Declaration of Helsinki) for studies involving humans.

Design of the Study:

Two Groups: Pre-test and Post-test Design. All participants assign randomly into two equal groups (A \& B). Group A: consisted of fifteen patients who received muscle energy technique 3 sessions per week for 8 weeks ${ }^{(6)}$. Group B: consisted of fifteen patients who received aerobic exercises (walking on the treadmill for $30 \mathrm{~min}$ ) 3 sessions per week for 8 weeks

\section{Assessment}

1. Detailed medical, obstetric, and menstrual histories were taken from each female before starting the study to confirm the absence of any contraindications that may interfere with the study.

2. Ultrasound assessment: The initial step in assessment before the beginning of the program. It has an important role in the evaluation to exclude the presence of any pelvic pathology and to exclude any associated complications. It is easily identified on standard two-dimensional (2D) TVUSG, it is costeffective and lacks a risk of radiation ${ }^{(9)}$.

3.Weight-Height Scale: It was measured while the patient wearing a thin layer of clothes for BMI calculation according to the following equation: $\mathrm{BMI}=$ weight/height ${ }^{2}\left(\mathrm{Kg} / \mathrm{m}^{2}\right)$ before starting the treatment program.

4. Visual analog scale (VAS): Before the intervention, menstrual pain was measured by mean of the visual analog scale to help patients to determine the intensity of pain by using a $10 \mathrm{~cm}$ horizontal line in which pain intensity was scored as follows: no pain $=0$, worst pain $=10$. The visual analog scale is reported to be a reliable outcome measure for pain evaluation, It allows graphic representation and numerical analysis of collected data ${ }^{(8)}$.

5. Menstrual Distress Questionnaire (MDQ): It is a 46-item self-report inventory that is used in the assessment of premenstrual, menstrual, and intermenstrual symptoms. The MDQ can distinguish cyclical from non-cyclical changes in physical symptoms, mood, behavior, and arousal. It identifies the type and intensity of the symptoms women experience during each phase of the menstrual cycle

\section{Interventions:}

Group A: consisted of fifteen patients who received muscle energy technique 3 sessions per week for 8 weeks.

Group B: consisted of fifteen patients who received aerobic exercises (walking on the treadmill for $30 \mathrm{~min}$ ) 3 sessions per week for 8 weeks.

All participants in both groups were evaluated before and after the treatment programs.

\section{Treatment Procedures}

\section{Group (A):}

MET of the Iliopsoas: The participants asked to assume supine lying on the edge of the plinth with the leg outside the plinth and holding their right knee against the chest while the therapist stands beside the patient and stabilizes the patient's left hip by the right hand and placing left hand just above the patient's left knee The patient is asked to flex the hip against the resistance for 10 seconds, Three seconds rest phase to allow relaxation. Three seconds stretch by slowly applies downward pressure. This procedure was repeated three times ${ }^{(\mathbf{1 0})}$.

MET of Piriformis muscle: The participants asked to assume a supine lying position, the treated leg was placed into flexion at the hip and knee and cross over the contralateral straight leg so that the foot of the treated leg rested on the table lateral to the contralateral knee while the therapist stands beside the patient at the side to be treated placing the right hand on the contralateral Anterior Superior Iliac Spine (ASIS) to prevent pelvic motion, while the other hand was placed against the lateral flexed knee The patient is asked to abduct the lateral flexed knee against resistance for 10 seconds, three seconds rest phase to allow relaxation. Three seconds stretch by slowly taking the treating side leg into adduction until the sense of resistance is noted. This procedure was repeated three times.

MET of Quadratus Lumborum muscle: The participants asked to assume a side lying position with the uppermost arm extended over the head to firmly grasp the top of the table while the therapist stands behind the patient at waist level On inhalation adducted the uppermost leg until the therapist palpate strong quadrates activity elevation, the patient is asked to hold the leg in this manner isometrically allowing gravity to provide resistance after 10 seconds contraction the patient was asked to hang leg slightly behind her over the back of the table. The therapist straddled this and cradling the pelvis with both hands leaning back to take out all the slack and to ease the pelvis away from the lower ribs during an exhalation. The stretch was held for 3 seconds. ${ }^{(11)}$.

MET of Erector Spinae muscle: The participants asked to assume sitting on the treatment table with legs hanging over the side while the therapist stands behind the patient placing his one knee on the plinth close to the 
patient, at the side towards which side bending and rotation will be introduced The therapist passed a hand in front of the patient's axilla on the side to which the patient was to be rotated. The patient was drawn into flexion, side bending, and rotation. When the patient has been taken to the comfortable limit of flexion, he was asked to look towards the direction from which rotation has been made while holding her breath for 7-10 seconds. The patient was then asked to release the breath. The practitioner waited for the patient's full exhalation and then took the patient further in all the directions of restriction, towards the new barrier.

\section{Group (B):}

Before starting the treatment program, each patient was informed about the benefits of aerobic exercise to gain her motivation and cooperation during the treatment course. She was advised to drink plenty of fluids before and after the exercise session and wear supportive, wellfitting running or walking shoes The Treadmill exercise program consisted of:

Warm-up phase: in which each participant walked at $80 \mathrm{~m} / \mathrm{min}$ at $0.0 \%$ grade for $5 \mathrm{~min}$.

A- Active phase: Treadmill speed was increased to $147 \mathrm{~m} / \mathrm{min}$ and grade was increased gradually until reached $25 \%$ grade for $20 \mathrm{~min}$.

B- Cool down phase: in which the treadmill speed and grade were decreased to $2.0 \mathrm{miles} / \mathrm{h}$ and $0.0 \%$ grade during a cool down period consisted of $5 \mathrm{~min}$ it should be mentioned that the intensity of exercises was equal for all the participants in this group. Each participant performed these exercises three times a week for two menstrual cycles. Using the treadmill had been taught to the participants according to the protocol. Patients attended exercise sessions 3 times/week.

\section{Statistical analysis:}

Descriptive statistics and t-test were conducted for comparison of the age, BMI, weight, and height of both groups. Unpaired t-test was conducted for comparison of pre and post-treatment mean values of VAS between groups. Paired t-test was conducted for comparison between pre and post-treatment mean values of VAS in each group. Paired t-test was conducted for comparison of VAS and MDQ premenstrual, menstrual, and intermenstrual among groups. T-test be was conducted for comparison of VAS and MDQ premenstrual, menstrual, and intermenstrual among both groups. The level of significance for all statistical tests was set at $\mathrm{p}<$ 0.05. All statistical measures were performed through (SPSS) version 25 for windows.

\section{RESULTS}

Table 1 shows that the mean age of group A was 28.33 \pm 3.24 years and that of group B was $26.73 \pm 2.4$ years with a mean difference of 1.6 years. There were no statistically significant differences between the studied groups in mean age.

Table 2 shows that there were no statistically significant differences between the studied groups in weight, height, and BMI.

Table 3 shows that there were no statistically significant differences between the studied groups in VAS score pretreatment but there was a statistically significant decrease in VAS score in Group A compared to Group B posttreatment for the favor of group A than group B. Regarding the differences between pretreatment measures \& post treatment measures in each group there was a statistically significant decrease in VAS score post treatment compared to pre treatment in both Group A \& Group B (by 62.47\% \& 32.96\% respectively).

Table 4 shows that there were no statistically significant differences in the pre treatment values of both groups in the menstrual distress questionnaire score 4 days before menstruation but there was a statistically significant decrease in the post treatment score of Group A compared to Group B for the favor of group A than group B. Regarding differences between pre treatment measures \& post treatment measures in each group the mean menstrual distress questionnaire score 4 days before menstruation post treatment of group A was 45.6 \pm 9.4 and that of group B was $95.07 \pm 11.9$ with mean difference 49.5 . There was a statistically significant decrease in score post treatment compared to pre treatment in both Group A \& Group B (by $65.53 \%$ \& $23.8 \%$ respectively.

Table 5 shows that there were no statistically significant differences between the pre treatment values of both groups in the menstrual distress questionnaire score $1^{\text {st }}$ day of menstruation but there was a statistically significant decrease in the post treatment score in Group A compared to Group B for the favor of group A than group B . Regarding differences between pre treatment measures \& post treatment measures in each group the mean menstrual distress questionnaire score 1st day of menstruation post treatment of group A was $39.67 \pm$ 8.12 and that of the group, B was $91.33 \pm 18.85$ with mean difference 51.66. There was a statistically significant decrease in score post treatment compared to pre treatment in both Group A \& Group B (by $67.55 \%$ $\& 24.36 \%$ respectively).

Table 6 shows that there were no statistically significant differences between the pre treatment values of both groups in the menstrual distress questionnaire score consequence 3 days of menstruation but there was a statistically significant decrease in the post treatment score in Group A compared to Group B for the favor of group A than group B. Regarding differences between pre treatment measures $\&$ post treatment measures in each group the mean menstrual distress questionnaire score consequence 3 days of menstruation post of group A was $14.53 \pm 4.57$ and that of group B was $48.43 \pm$ 10.06 with mean difference 33.9. There was a statistically significant decrease in score post tretment compared to pre treatment in both Group A \& Group B (by $80.28 \% \& 29.86 \%$ respectively).

Table (1): Comparison of the mean age between both groups 


\begin{tabular}{|c|l|c|c|c|c|c|}
\hline \multicolumn{2}{|c|}{ Variable } & $\begin{array}{c}\text { Group A } \\
(\mathbf{n = 1 5})\end{array}$ & $\begin{array}{c}\text { Group B } \\
(\mathbf{n = 1 5})\end{array}$ & MD & T & P-value \\
\hline Age: (years) & $\overline{\mathrm{X}} \pm$ SD & $28.33 \pm 3.24$ & $26.73 \pm 2.4$ & 1.6 & 1.54 & 0.14 \\
& Range & $25-35$ & $25-33$ & & & NS \\
\hline
\end{tabular}

SD: Stander deviation, MD: Mean difference t: independent t-test,

NS: Nonsignificant $(\mathrm{P}>0.05) \quad \overline{\mathrm{X}}$ : Mean

Table (2): Comparison of the mean BMI between both group

\begin{tabular}{|l|l|c|c|c|c|c|}
\hline \multicolumn{2}{|c|}{ Variable } & $\begin{array}{c}\text { Group A } \\
(\mathbf{n = 1 5})\end{array}$ & $\begin{array}{c}\text { Group B } \\
(\mathbf{n = 1 5})\end{array}$ & MD & T & P-value \\
\hline Weight: $(\mathrm{kg})$ & $\overline{\mathrm{X}} \pm \mathrm{SD}$ & $61.07 \pm 3.84$ & $60.29 \pm 6.84$ & 0.78 & 0.38 & 0.71 \\
& Range & $56-70$ & $48-74.4$ & & & NS \\
\hline Height: $(\mathrm{cm})$ & $\overline{\mathrm{X}} \pm \mathrm{SD}$ & $161 \pm 5.79$ & $161.13 \pm 5.32$ & -0.13 & 0.07 & 0.95 \\
& Range & $150-170$ & $152-171$ & & & NS \\
\hline BMI: & $\bar{X} \pm \mathrm{SD}$ & $23.48 \pm 1.48$ & $23.17 \pm 1.71$ & 0.31 & 0.53 & 0.60 \\
$\left(\mathrm{~kg} / \mathrm{m}^{2}\right)$ & Range & $21.25-25.7$ & $20.24-25.44$ & & & NS \\
\hline
\end{tabular}

SD: Stander deviation, MD: mean difference t: independent t-test

NS: Nonsignificant $(\mathrm{P}>0.05) \quad \overline{\mathrm{X}}$ : Mean

Table (3): Comparison between pre and post treatment mean values of VAS of both groups

\begin{tabular}{|c|c|c|c|c|c|}
\hline \multicolumn{2}{|c|}{ Variable } & $\begin{array}{c}\text { Group A } \\
(n=15)\end{array}$ & $\begin{array}{c}\text { Group B } \\
(n=15)\end{array}$ & $\mathbf{T}$ & P-value \\
\hline $\begin{array}{l}\text { VAS pre } \\
\text { treatment: }\end{array}$ & $\begin{array}{l}\bar{X} \pm S D \\
\text { Range }\end{array}$ & $\begin{array}{c}6.6 \pm 1.54 \\
4-9\end{array}$ & $\begin{array}{c}7.2 \pm 1.21 \\
5-9\end{array}$ & 1.18 & $\begin{array}{c}0.25 \\
\mathrm{NS}\end{array}$ \\
\hline $\begin{array}{l}\text { VAS post } \\
\text { treatment: }\end{array}$ & $\begin{array}{l}\overline{\mathrm{X}} \pm \mathrm{SD} \\
\text { Range }\end{array}$ & $\begin{array}{c}2.53 \pm 1.25 \\
1-5\end{array}$ & $\begin{array}{c}4.87 \pm 1.55 \\
3-8\end{array}$ & 4.54 & $\begin{array}{c}<0.001 \\
* *\end{array}$ \\
\hline \multicolumn{2}{|c|}{ Paired t } & 13.54 & 8.12 & & \\
\hline \multicolumn{2}{|r|}{$\mathrm{P}$} & $<0.001 * *$ & $<0.001 * *$ & & \\
\hline \multicolumn{2}{|c|}{$\%$ of reduction } & $62.47 \%$ & $32.96 \%$ & & \\
\hline
\end{tabular}

SD: Stander deviation, $\quad \mathrm{t}$ : independent t-test, Paired t: Paired t-test

$\overline{\mathrm{X}}$ : Mean

NS: Nonsignificant $(\mathrm{P}>0.05) \quad$ **: Highly significant $(\mathrm{P}<0.001)$

Table (4): Comparison between pre and post treatment scores of MDQ 4 days before menstruation of the studied groups

\begin{tabular}{|c|c|c|c|c|c|}
\hline \multicolumn{2}{|c|}{ Variable } & $\begin{array}{c}\text { Group A } \\
(n=15)\end{array}$ & $\begin{array}{c}\text { Group B } \\
(n=15)\end{array}$ & $\mathbf{T}$ & P-value \\
\hline $\begin{array}{l}\text { Premenstrual } \\
\text { reading pre } \\
\text { treatment: }\end{array}$ & $\begin{array}{l}\overline{\mathrm{X}} \pm \mathrm{SD} \\
\text { Range }\end{array}$ & $\begin{array}{c}133.13 \pm 10.86 \\
110-150\end{array}$ & $\begin{array}{c}125 \pm 13.40 \\
100-146\end{array}$ & 1.83 & $\begin{array}{l}0.08 \\
\mathrm{NS}\end{array}$ \\
\hline $\begin{array}{l}\text { Premenstrual } \\
\text { reading post } \\
\text { treatment: }\end{array}$ & $\begin{array}{l}\bar{X} \pm S D \\
\text { Range }\end{array}$ & $\begin{array}{c}45.6 \pm 9.40 \\
30-60\end{array}$ & $\begin{array}{c}95.07 \pm 11.90 \\
80-120\end{array}$ & 12.64 & $\begin{array}{c}<0.001 \\
* *\end{array}$ \\
\hline \multicolumn{2}{|c|}{ Paired $t$} & 23.75 & 12.89 & & \\
\hline \multicolumn{2}{|c|}{$\mathrm{P}$} & $<0.001 * *$ & $<0.001 * *$ & & \\
\hline \multicolumn{2}{|c|}{$\%$ of reduction } & $65.53 \%$ & $23.8 \%$ & & \\
\hline
\end{tabular}

SD: Stander deviation, $\quad$ t: independent t-test, $\quad$ Paired t: Paired t-test

$\bar{X}$ : Mean

NS: Nonsignificant $(\mathrm{P}>0.05) \quad$ **: Highly significant $\quad(\mathrm{P}<0.001)$

Table (5): Comparison between pre and post treatment scores of MDQ 1st day of menstruation of the studied groups

\begin{tabular}{l|l} 
Group A & Group B
\end{tabular}




\begin{tabular}{|c|c|c|c|c|c|}
\hline \multicolumn{2}{|c|}{ Variable } & $(n=15)$ & $(n=15)$ & $\mathbf{T}$ & P-value \\
\hline $\begin{array}{l}1^{\text {st }} \text { day MDQ } \\
\text { reading pre } \\
\text { treatment: }\end{array}$ & $\begin{array}{l}\bar{X} \pm S D \\
\text { Range }\end{array}$ & $\begin{array}{c}125.6 \pm 22.25 \\
72-148\end{array}$ & $\begin{array}{c}121.2 \pm 13.86 \\
94-140\end{array}$ & 0.65 & $\begin{array}{l}0.52 \\
\text { NS }\end{array}$ \\
\hline $\begin{array}{l}1^{\text {st }} \text { day MDQ } \\
\text { reading post } \\
\text { treatment: }\end{array}$ & $\begin{array}{l}\bar{X} \pm S D \\
\text { Range }\end{array}$ & $\begin{array}{c}39.67 \pm 8.12 \\
30-50\end{array}$ & $\begin{array}{c}91.33 \pm 18.85 \\
50-120\end{array}$ & 9.75 & $\begin{array}{c}<0.001 \\
* *\end{array}$ \\
\hline \multicolumn{2}{|c|}{ Paired $t$} & 15.38 & 6.44 & & \\
\hline \multicolumn{2}{|c|}{$\mathrm{P}$} & $<0.001 * *$ & $<0.001 * *$ & & \\
\hline \multicolumn{2}{|c|}{$\%$ of reduction } & $67.55 \%$ & $24.36 \%$ & & \\
\hline
\end{tabular}

SD: Stander deviation, $t$ : independent t-test, $\quad$ Paired t: Paired t-test $\quad \overline{\mathrm{X}}$ : Mean

NS: Nonsignificant $(\mathrm{P}>0.05) \quad$ **: Highly significant $(\mathrm{P}<0.001)$

Table (6): Comparison between pre and post treatment values of MDQ consequence 3 days of menstruation of both group

\begin{tabular}{|c|c|c|c|c|c|}
\hline \multicolumn{2}{|c|}{ Variable } & $\begin{array}{c}\text { Group A } \\
(n=15)\end{array}$ & $\begin{array}{c}\text { Group B } \\
(n=15)\end{array}$ & $\mathbf{T}$ & P-value \\
\hline $\begin{array}{l}3 \text { days } \\
\text { consequence MDQ } \\
\text { reading pre } \\
\text { treatment: }\end{array}$ & $\begin{array}{l}\bar{X} \pm \text { SD } \\
\text { Range }\end{array}$ & $\begin{array}{c}74.53 \pm 9.36 \\
60-85\end{array}$ & $\begin{array}{c}70.60 \pm 9.09 \\
55-85\end{array}$ & 1.17 & $\begin{array}{l}0.25 \\
\mathrm{NS}\end{array}$ \\
\hline $\begin{array}{l}3 \text { days } \\
\text { consequence MDQ } \\
\text { reading post } \\
\text { treatment: }\end{array}$ & $\begin{array}{l}\overline{\mathrm{X}} \pm \mathrm{SD} \\
\text { Range }\end{array}$ & $\begin{array}{c}14.53 \pm 4.57 \\
10-21\end{array}$ & $\begin{array}{c}48.43 \pm 10.06 \\
33-66\end{array}$ & 11.82 & $\begin{array}{c}<0.001 \\
* *\end{array}$ \\
\hline \multicolumn{2}{|c|}{ Paired t } & 22.88 & 6.35 & & \\
\hline \multicolumn{2}{|c|}{$\mathrm{P}$} & $<0.001 * *$ & $<0.001 * *$ & & \\
\hline \multicolumn{2}{|c|}{$\%$ of reduction } & $80.28 \%$ & $29.86 \%$ & & \\
\hline
\end{tabular}

SD: Stander deviation, $\quad \mathrm{t}$ : independent t-test, $\quad$ Paired t: Paired t-test, $\quad \overline{\mathrm{X}}$ : Mean

NS: Nonsignificant $(\mathrm{P}>0.05) \quad * *$ : Highly significant $(\mathrm{P}<0.001)$

\section{DISCUSSION}

The results of the present work revealed that there was a significant decrease in the values of visual analog scale and menstrual distress questionnaire post treatment in the Group (A) compared with that pre treatment values, also there was a significant decrease in VAS and MDQ post treatment values compared with the pre treatment values in the Group (B). Although both treatment techniques were found to be effective when comparing both groups, it has been found that there were statically significant differences between both groups as there was a more significant decrease in the post treatment values of VAS and MDQ of the Group (A) compared with that of the Group (B). The Muscle Energy Technique is a better treatment intervention compared to Aerobic Exercise on chronic cyclic pelvic pain.

The significant reduction in the pain intensity in the Group (A) in comparison to the Group (B), who received MET is in agreement with Fryer (12) who stated that according to the gate-control theory, mechanoreceptor afferents carried by large-diameter axons suppress nociception afferents in the dorsal horn of the spinal cord, joint movement and isometric muscle contraction will stimulate joint and muscle proprioceptors and therefore give pain alleviation this was supported by the study of Degenhard $\boldsymbol{e t}$ al. ${ }^{(13)}$ who reported that we can improve myofascial trigger points by applying different forms of MET.
Following activation of muscle and joint mechanoreceptors during isometric contractions, MET has another explanation for pain mitigation, which is partially done via nociceptive inhibition via both ascending and descending neurological pathways. Muscle contraction also promotes fluid flow, enhancing venous and lymphatic drainage from interstitial regions and lowering concentrations of toxins. This explanation comes in agreement with Mc Partland ${ }^{(14)}$.

Chaitow ${ }^{(10)}$ Stated that a shortened, contracted, or spastic muscle can be lengthened using MET. It also has a significant effect on strengthening a physiologically weakened muscle or set of muscles, which aids in the reduction of localized edema and the mobilization of a restricted-mobility articulation.

A study was done by Kumar and Singh ${ }^{(15)}$ also concluded and supported the efficacy of MET in reducing pain and disability in patients with nonspecific low back pain when MET was given 3 times a week for 3 weeks. This technique Also, the result of this study was confirmed with that of Roland ${ }^{(16)}$ who stated that muscle energy technique is effective in relieving pain, improving range of motion, and reducing disability in subjects with recurrent low back pain

Choi and Yoon ${ }^{(17)}$ reported that pain decreased from 4 points to 2 points when they applied MET to women in their twenties who complained about buttock and lower extremity pain due to piriformis muscle syndrome. And this 
was supported by a study done by Vijaya et al. ${ }^{(18)}$ which concluded that muscle energy technique on quadratus lumborum is more effective than active posterior pelvic tilt exercises in reducing pain and disability among acute low back pain patients.

The outcome of the present study is similar to the study by Mahajan et al. ${ }^{(19)}$ which favored the use of MET when it compared with static stretching for mechanical neck pain and showed that MET had a marked reduction in neck pain and improvement in neck functions.

The reduction in pain intensity in the Group (B), who received aerobic exercise is in agreement with Eloise and Eileen, ${ }^{(20)}$ who reported that exercise lowers the feeling of pain, lowers muscle spasms, and improves cardiovascular fitness by lowering stimuli that compete with pain. In addition, Kaur et al. ${ }^{(21)}$ shown that it can reduce sympathetic activity and tension by releasing endorphins that boost the pain threshold, hence lowering symptoms

Cheng and Lin ${ }^{(22)}$ reported that aerobic exercise relieves pain by lowering tension and psychological stress, which leads to the release of pain-relieving endorphins. During exercise, pelvic blood circulation and local metabolism are improved, which is another method.

Results of this study supported by Dehnavi et $\boldsymbol{a l}^{(\mathbf{2 3})}$ who showed that the severity of menstrual pain decreased at the end of 8 weeks of aerobic exercise

Results of this study also agreed with Shavandi $\boldsymbol{e t}$ al. (24) who examined the effect of 8 weeks of isometric exercises on primary dysmenorrhea in female students and concluded that performing isometric exercises (including abdominal, pelvic, and groin enhancement exercises) is effective in reducing the severity and duration of pain and the rate of use of medication in females suffer from dysmenorrhea Proctor and Farquhar (25) stated that physical exercise may play role in reducing pelvic pain caused by excessive prostaglandins release as it works by improving blood flow at the pelvic level as well as stimulating the release of endorphins it acts as non-specific analgesics

Samadi et al. (26) examined the effect of 8 weeks of regular, moderate aerobic exercise on physical and psychological menstrual cycle symptoms they revealed that women who frequently exercise might be protected from deterioration of mood before and during menstruation Mavash et al. ${ }^{(27)}$ added that the increase in the blood flow and metabolism of the uterus during exercise may be effective in the reduction of pelvic pain that happens during menstruation.

Our results agreed with Wilson and Payton ${ }^{(6)}$ who listed that MET is more effective in decreasing pelvic pain and may improve physical function in the short-term duration

\section{CONCLUSION}

It can be concluded that both muscle energy technique and aerobic exercise will improve chronic cyclic pelvic pain. Muscle energy technique resulted in better improvement as compared to aerobic exercise on chronic cyclic pelvic pain.

\section{REFERENCES}

1. Bordman R, Jackson B (2006): Approach to chronic pelvic pain. Can Fam Physician, 52: 1556-1562.

2. Arleen H, Song M, Arnold P et al. (2005): Adolescent Chronic Pelvic Pain. J Pediatr Adolesc Gynecol., (18): 371-377.
3. Won H, Abbott J (2010): Optimal management of chronic cyclic pelvic pain. Int J women, 2(3):263-277.

4. Mohammadi B, AzamianJazi A, Fathollahi F et al. (2012): The Effect of Aerobic exercise training and Detraining on Some of the Menstrual Disorders in Nonathlete Students. The Horizon of Medical Sciences, 18 (2): 5-9.

5. Thomas E, Cavallaro A, Mani D et al. (2019): The efficacy of muscle energy techniques in symptomatic and asymptomatic subjects: a systematic review. Chiropr Man Therap., 27:35-42.

6. Wilson E, Payton O (2003): Muscle energy technique in patients with acute low back pain, A pilot clinical trial. J Orthop Sports Physiotherapy, 33(9): 502-512.

7. Odole A, Akinpelu A (2009): Translation and alternate forms reliability of the visual analog scale in the three major Nigerian languages. Internet Journal of Allied Health Sciences and Practice, 7(3): 13-18.

8. Larroy C (2002): Comparing visual-analog and numeric scales for assessing menstrual pain. Behav Med Winter, 27(4):179-81.

9. Peri N, Graham D, Levine D (2007): Imaging of intrauterine contraceptive devices. Journal of Ultrasound in Medicine, 26(10): 1389-1401.

10. Chaitow L (2006): Muscle energy techniques. $3^{\text {rd }}$ ed, Churchill, British library London, Livingston, Pp. 110129. https://medisport.com.ua/ image/data/courses/ library/Muscle\%20Energy\%20Techniques3rd\%20Edition.pdf

11. Shivangi S, Sheetal K, Sonia $P$ (2018): Effects of Muscle Energy Technique versus Mobilization on Pain and Disability in Post-Partum Females with Sacroiliac Joint Dysfunction. Indian Journal of Health Sciences and Care, 5(1): 11-17.

12. Fryer G (2000): Muscle energy concepts - a need for change. Journal of Osteopathic Medicine, 3 (2): 54-59, 817-4.

13. Degenhardt B, Darmani N, Johnson J (2007): Role of osteopathic manipulative treatment in altering pain biomarkers. A Pilot Study. J Am Osteopath Assoc., 107: 387-400.

14. McPartland J (2008): The endocannabinoid system: an osteopathic perspective. J Am Ost Assoc., 108(10):586600.

15. Kumar A, Singh D (2015): Effect of Muscle energy technique on pain and disability in patients with nonspecific back pain. Indian J Physical Therapy, 3(2):4044.

16. Roland M (2012): Comparison of trunk muscle stabilization Exercises and muscle energy technique in recurrent low back pain. A randomized Clinical trial. The Egyptian Journal of Neurology, Psychiatry, and Neurosurgery, 55: 77-83.

17. Choi Y, Yoon I (2010): A clinical case study on piriformis syndrome with oriental medical treatment and muscle energy techniques. Journal of Korean Medicine Rehabilitation, 20(2):209-17

18. Vijaya S, Franklin S, Senthil K et al. (2020): Effect of muscle energy technique on quadrates lamborum in acute low back pain patients. IDC International Journal, 7(4):33-36.

19. Mahajan R, Kataria C, Bansal K (2012): Comparative effectiveness of muscle energy technique and static stretching for treatment of subacute mechanical neck pain. Int J Health Rehabil Sci., 1(16)-24-29. 
20. Eloise C, Eileen $M$ (2000): Mangement of pain. $1^{\text {st }}$ Ed, Lippincott William \& Wilkins, Philadelphia, pp. 155161.

21. Kaur S, Kaur P, Shanmugam S et al. (2014): To compare the effect of stretching and core strengthening exercises on Primary Dysmenohrrea in Young females. IOSR Journal of Dental and Medical Sciences, 13 (6): 22-32.

22. Cheng H, Lin Y (2011): Selection and efficacy of selfmanagement strategies for dysmenorrhea in young Taiwanese women. Journal of Clinical Nursing, 20(7-8): 1018-1025.

23. Dehnavi Z, Jafarnejad F, Kamali Z (2018): The Effect of aerobic exercise on primary dysmenorrhea. A clinical trial study. Journal of Education and Health Promotion, 7:170-185.
24. Shavandi N, Taghian F, Soltani V (2010): The effect of isometric exercise on primary dysmenorrhea. Arak UNi Med Sci., 13 (1): 71-7.

25. Proctor M, Farquhar C (2006): Diagnosis and management of dysmenorrhoea. British Medical Journal, 332(7550): 1134-1138.

26. Samadi Z, Taghian F, Valiani M (2013): The effects of 8 weeks of regular aerobic exercise on the symptoms of premenstrual syndrome in non-athlete girls. Iran $\mathbf{J}$ Nurs Midwifery Res., 18(1):14-19,

27. Mahvash N, Eidy A, Mehdi K et al. (2012): The effect of physical activity on primary dysmenorrhea of female university students. World Applied Sciences Journal, 17(10): 1246-1252. 